\title{
Should You Invest in Stocks of Racially Diverse Companies?
}

\author{
D.K. Malhotra \\ Thomas Jefferson University \\ Jing Zhang
Thomas Jefferson University
}

In today's business environment, many firms passionately debate the impact of racial and gender diversity, particularly how a diverse workforce affects analytical thinking and innovation. To learn more, we examined the effects of diversity on the risk-adjusted performance of stocks from the 33 most diverse corporations. Using traditional portfolio performance indicators, we examined risk-adjusted performance from 2000 to 2020. We found that diverse companies outperformed stock market benchmark indices in most cases. We also discovered that an equally-weighted portfolio of the 33 most diverse firms outperformed the risk-adjusted performance of the Dow Jones Industrial Average (DJIA), the Standard \& Poor 500 index (S\&P500), and the NASDAQ.

Keywords: diversity, portfolio performance, Sharpe ratio, Sortino ratio, Omega ratio, Fama-French model

\section{INTRODUCTION}

In today's business environment, the impact of racial and gender diversity on firms is a topic of passionate debate. The argument over diversity focuses on how a diverse workforce impacts analytical thinking and innovation. Many business leaders have suggested that companies will need a diverse workforce if they want to survive and preserve their competitive edge, but there is little research on the topic.

According to a report from McKinsey \& Company, companies that are more diverse are better positioned to recruit top talent and to improve their customer orientation, employee contentment, and decision making, leading to a virtuous cycle of increasing returns. Other types of diversity, such as age, sexual orientation, and global viewpoints, are also likely to give a competitive advantage to firms that attract and retain diverse employees (https://www.mckinsey.com/business-functions/organization/ourinsights/why-diversity-matters\#).

Does diversity lead to better stock price performance? According to a Bank of America (BofA) report, shares in companies with greater gender, ethnic, and racial diversity deliver higher returns to investors. Furthermore, S\&P 500-listed companies with above-average gender diversity on their boards have a 15\% higher return on equity compared to firms with less diverse boards. The BofA report also noted that S\&P 500 companies with a more ethnically and racially diverse workforce outperform firms with a less diversified workforce by $8 \%$ (https://www.cnbc.com/2021/03/09/bofa-stocks-with-the-greatestdiversity.html). 
But researchers have struggled to demonstrate a causal link between diversity and financial performance indicators such as earnings or market share. To expand the evidence on this topic, we examined the effects of diversity on the risk-adjusted performance of the stocks of the 33 most diverse corporations. Our research assessed the risk-adjusted performance of several firms, as well as an equallyweighted portfolio of stocks from various firms and compared it to market indexes such as the DJIA, S\&P 500 , and NASDAQ.

The rest of the paper is organized as follows: Section II describes the previous studies that have examined the issue of diversity and stock market performance; Section III discusses the traditional portfolio performance models such as Sharpe ratio, Sortino ratio, Omega ratio, and Fama-French models; Section IV provides the data used in this study; Section V discusses the empirical results; and Section VI summarizes and concludes our study.

\section{PREVIOUS STUDIES}

Previous research has shown that workplace diversity is generally beneficial to business, including corporate profits and earnings. Herring (2009) examined the impact of racial and gender diversity on business performance and found that diversity was associated with increased sales revenue, more customers, greater market share, and greater relative profits. Roberson and Park (2007) used longitudinal data for 100 firms to test hypotheses related to the effects of diversity reputation and leader racial diversity on firm financial outcomes. They found that diversity reputation has a positive relationship with book-tomarket equity and leader diversity had a curvilinear, U-shaped relationship with revenues, net income, and book-to-market equity. Andrevski, Richard, Shaw, Jason, and Ferrier (2014) examined the mediating role of competitive intensity in the relationship between managerial racial diversity and firm performance (i.e., market share gain, average stock return) and found that racial diversity related to firm performance via firms' capacity to compete intensively (i.e., to introduce new competitive actions frequently). An earlier study by Richard (2000) examined the link between cultural diversity, business strategy, and firm performance and found that cultural diversity does add value and contributes to a firm's competitive advantage. These findings suggest that economic benefits generated from diversity reputation primarily derive from capital rather than product markets. Furthermore, they indicate that firm performance declines with increases in the representation of racial minorities in leadership up to a point, beyond which further increases in diversity are associated with increases in performance.

Our study contributes to the existing body of knowledge by examining stock price performance of 33 of the most diverse corporations and comparing their risk-adjusted performance to benchmark indexes. We also examine an equally-weighted portfolio of 33 of the most diverse firms and compared it to market indexes.

\section{MODEL}

To assess risk-adjusted performance, we estimated Sharpe ratio (1966), Sortino ratio (1991), Omega ratio (2002), Fama-French three factor, Fama-French five factor, and Carhart four factor models for each company in the sample, an equally weighted portfolio of 33 diverse companies, Dow Jones Industrial Average (DJIA), S\&P 500, and NASDAQ from January 2000 to December 2020.

\section{Sharpe Ratio}

The Sharpe ratio assesses how well an investment compensates its investors for each unit of risk they

take. The higher the Sharpe ratio, the more successful the investment. The Sharpe (1966) measure is defined as the ratio of risk premium to portfolio standard deviation, as shown in equation 1.

Sharpe Ratio $=\frac{R_{P}-R_{f}}{\sigma_{P}}$ 
where $\quad \mathrm{Rp}=$ the portfolio return

$\mathrm{Rf}=$ the risk-free rate

$\sigma \mathrm{P}=$ standard deviation of the portfolio

The Sharpe ratio compares the performance of an equity investment to that of a risk-free investment, after considering the increased risk associated with holding an equity investment. When the Sharpe ratio is positive, it means that equity investment will yield a higher risk-adjusted return. A risk-adjusted return rating of one or above is considered favorable.

The Sharpe ratio addresses the challenge of determining the breadth of the results since the more the diversity, the lower the standard deviation of the portfolio return. Because company-specific effects cancel out, the addition of securities decreases the standard deviation of returns. However, the Sharpe ratio has a benchmark problem since the proxy for the market portfolio decides the amount of the market portfolio's standard deviation. As a result, the value of the Sharpe measure for the benchmark portfolio, as well as the comparison with the Sharpe measure for the portfolio in question, will be impacted.

\section{Sortino Ratio}

Sortino ratio (1991) is a Sharpe ratio variation. Sortino differentiates between good and bad volatility in a portfolio's total volatility. We calculated the standard deviation of negative portfolio returns, or downside deviation, instead of total standard deviation. The higher the Sortino ratio, the better the performance of a portfolio. Equation 2 depicts the Sortino ratio.

Sortino Ratio $=\frac{R_{P}-R_{f}}{\sigma_{d}}$

where RP and Rf are described as above and $\sigma \mathrm{d}$ is the standard deviation of portfolio's negative returns.

\section{Omega Ratio}

The Omega ratio, as developed by Shadwick and Keating (2002), is a technique of measuring the performance of financial assets based on the amount of returns they produce in exchange for the risk of investing in them. Omega ratio is a ratio of weighted gain to weighted loss. Expected returns are divided into two groups by this indicator: 1) gains and losses, or 2) returns that are higher than the predicted average (the upside) or lower (the downside). As a result, the omega ratio is the ratio of positive returns (good) to negative returns (bad). The Sharpe ratio only analyzes the first two moments of the return distribution (mean and variance), but the Omega ratio takes all of them into account. The Omega ratio is an alternative asset efficiency metric that gives investors information that the Sharpe ratio does not.

$\Omega=\frac{\int_{r}^{b}(1-F(x)) d x}{\int_{a}^{r} F(x) d x}$

where $\mathrm{F}(\mathrm{x})$ is the cumulative probability distribution (i.e., the probability that a return will be less than $\mathrm{x}$ ), $\mathrm{r}$ is a threshold value selected by the investor, and $\mathrm{a}$ and $\mathrm{b}$ are the investment intervals. It is effectively equal to the probability-weighted gains divided by the probability-weighted losses after a threshold.

\section{Fama-French Models}

The three-factor model developed by Fama and French (1993) is the most extensively used multi-factor model for estimating portfolio efficiency, according to Elton, Gruber, and Blake (2011). Three variablesexcess market return, size factor, and value vs. growth factor-account for nearly $90 \%$ of diversified portfolio results (as they are associated with risk), according to Fama and French.

We use monthly returns are used to estimate the following regression

$$
R_{i, t}-R_{f, t}=\alpha_{i}+\beta_{m, t}\left(R_{m, t}-R_{f, t}\right)+\beta_{s} S M B_{t}+\beta_{v} H M L_{t}+\varepsilon_{i, t}
$$


where $\mathrm{Ri}, \mathrm{t}=$ the percentage return to company $\mathrm{i}$ in month $\mathrm{t}$.

$\mathrm{Rf}, \mathrm{t}=\mathrm{US} \mathrm{T}$-bill rate for month $\mathrm{t}$.

$\mathrm{Rm}, \mathrm{t}=$ return on CRSP value-weighted index for month $\mathrm{t}$.

$\mathrm{SMBt}=$ realization on capitalization factor (small-cap return minus large-cap return) for month $\mathrm{t}$. $\mathrm{HMLt}=$ realization on value factor (value return minus growth return) for month $\mathrm{t}$. $\varepsilon i, t=$ an error term.

Small company stocks will have a positive loading on SMB (positive slope, $\beta$ s), whereas big-company stocks tend to have a negative loading. Similarly, a positive estimate on $\beta \mathrm{v}$ indicates sensitivity to the value factor and a negative estimate indicates sensitivity to the growth factor. A positive intercept $(\alpha)$ would indicate superior performance, whereas a negative intercept would indicate underperformance, compared to the three-factor model.

\section{Carhart Four-Factor Model}

Carhart's (1997) four-factor model is also used as a performance benchmark. The Carhart four-factor model is similar to the Fama-French three-factor model, but it includes an additional factor for momentum (MOM), which is the return difference between a portfolio of past 12-month winners and a portfolio of past 12-month losers. The four-factor model is consistent with a model of market equilibrium with four risk factors.

The model is as follows:

$R_{i, t}-R_{f, t}=\alpha_{i}+\beta_{m, t}\left(R_{m, t}-R_{f, t}\right)+\beta_{s} S M B_{t}+\beta_{v} H M L_{t}+\beta_{m} \mathrm{MOM}+\varepsilon_{i, t}$

Here also, a positive alpha would indicate superior performance, whereas a negative alpha would indicate underperformance, compared to the four-factor model.

\section{Fama-French Five Factor Model}

The Fama/French 5 factors $(2 \times 3)$ are constructed using the 6 value-weight portfolios formed on size and book-to-market, size and operating profitability, and size and investment. In addition to the three factors mentioned above in three-factor model, the five-factor model also includes RMW (Robust Minus

Weak) as the average return on the two robust operating profitability portfolios minus the average return on the two weak operating profitability portfolios.

RMW =1/2 (Small Robust + Big Robust) $-1 / 2$ (Small Weak + Big Weak)

CMA (Conservative Minus Aggressive) is the average return on the two conservative investment portfolios minus the average return on the two aggressive investment portfolios

$\mathrm{CMA}=1 / 2($ Small Conservative + Big Conservative) $-1 / 2($ Small Aggressive + Big Aggressive $)$

\section{DATA}

Diverse companies were identified by Diversity, Inc. (https://www.diversityinc.com/). The company identifies the top 50 most diverse companies each year. Out of the 50 most diverse companies identified, 33 are publicly traded companies for which stock price data was available from January 2000 onwards. We obtained stock price data for each publicly-traded, diverse company from Yahoo finance for January 2000 through December 2020. 


\section{List of Companies}

\begin{tabular}{|l|l|}
\hline Names of Company & Ticker Symbol \\
\hline Marriott International, Inc. & MAR \\
\hline Eli Lilly and Company & LLY \\
\hline ADP & ADP \\
\hline Mastercard & MA \\
\hline Comcast NBCUniversal & CMCSA \\
\hline Abbott & ABT \\
\hline Toyota Motor North America, Inc. & TM \\
\hline Wells Fargo & WFC \\
\hline Target & TGT \\
\hline Northrop Grumman Corporation & NOC \\
\hline Procter \& Gamble & PG \\
\hline The Hershey Company & HSY \\
\hline CVS Health & CVS \\
\hline Humana & HUM \\
\hline Southern Company & SO \\
\hline The Boeing Company & BA \\
\hline Exelon Corporation & EXC \\
\hline Allstate Insurance Company & ALL \\
\hline Walmart Inc. & WMT \\
\hline Medtronic plc & MDT \\
\hline The Kellogg Company & K \\
\hline KeyBank & KEY \\
\hline Colgate-Palmolive & CL \\
\hline AIG & AIG \\
\hline Ecolab Inc. & ECL \\
\hline U.S. Bank & USB \\
\hline Cigna & CI \\
\hline HP Inc. & HPQ \\
\hline McCormick \& Company & MKC \\
\hline Moody's Corporation & MCO \\
\hline AstraZeneca & AZN \\
\hline HSBC & HSBC \\
\hline Capital One Financial Corporation & COF \\
\hline & \\
\hline
\end{tabular}

Table 1 provides summary statistics of the variables used in this study. 
TABLE 1

SUMMARY STATISTICS

\begin{tabular}{|c|c|c|c|c|c|c|c|c|c|c|c|}
\hline & MAR & LLY & $A D P$ & CMCSA & ABT & TM & WFC & TET & NOC & PG & TD \\
\hline Mean & $1.3 \%$ & $0.9 \%$ & $0.9 \%$ & $0.8 \%$ & $11 \%$ & $0.5 \%$ & $0.7 \%$ & $1.1 \%$ & $1.4 \%$ & $0.7 \%$ & $1.1 \%$ \\
\hline 5td. Dev. & $8.8 \%$ & $7.0 \%$ & $6.0 \%$ & $7.0 \%$ & $5.7 \%$ & $6.2 \%$ & 8.26 & $7.9 \%$ & $6.8 \%$ & $5.1 \%$ & $7.0 \%$ \\
\hline Kurtosis & $429.7 \%$ & $331.7 \%$ & $105.2 \%$ & $6.1 \%$ & $68.4 \%$ & 230.896 & 612.196 & $54.1 \%$ & $304.0 \%$ & $949.4 \%$ & $253.2 \%$ \\
\hline Skewness & $29.7 \%$ & $13.0 \%$ & $10.3 \%$ & $-27.2 \%$ & $-45.5 \%$ & 60.496 & 1.896 & $37.3 \%$ & $2.4 \%$ & $-164.1 \%$ & $5.3 \%$ \\
\hline Minimum & $-39.4 \%$ & $-29.7 \%$ & $-17.7 \%$ & $-19.7 \%$ & $-20.7 \%$ & -17.196 & $-36.07 \%$ & $-20.0 \%$ & $-22.5 \%$ & $-35.4 \%$ & $-24.3 \%$ \\
\hline Maximum & $44.8 \%$ & $31.6 \%$ & $22.7 \%$ & $19.5 \%$ & $16.7 \%$ & $27.9 \%$ & $40.58 \%$ & $26.9 \%$ & $33.9 \%$ & $11.8 \%$ & $31.0 \%$ \\
\hline \multirow[t]{3}{*}{ N } & 252 & 252 & 252 & 252 & 252 & 252 & 252 & 252 & 252 & 252 & 252 \\
\hline & & & & & & & & & & & \\
\hline & the & ens & mive & Ju & Dar & Lo & AcL & vorin & (MDT & $n$ & NLT \\
\hline Mean & $1.1 \%$ & $0.9 \%$ & $2.1 \%$ & $1.1 \%$ & $13 \%$ & $0.8 \%$ & $1.1 \%$ & $0.6 \%$ & $0.8 \%$ & $0.7 \%$ & $0.6 \%$ \\
\hline 5td. Dev. & $5.9 \%$ & $7.5 \%$ & $10.3 \%$ & $4.9 \%$ & $9.3 \%$ & 6.196 & $7.7 \%$ & $5.5 \%$ & $6.1 \%$ & $5.2 \%$ & $8.8 \%$ \\
\hline Kurtosis & $294.6 \%$ & $178.1 \%$ & $303.9 \%$ & $185.4 \%$ & $461.2 \%$ & $177.88 \%$ & $638.1 \%$ & $114.1 \%$ & $210.0 \%$ & $290.7 \%$ & $358.4 \%$ \\
\hline Skewness & $62.9 \%$ & $-23.6 \%$ & $-4.5 \%$ & $-12.1 \%$ & $-35.6 \%$ & $-11.5 \%$ & -82.476 & $-24.9 \%$ & $-13.8 \%$ & $-13.3 \%$ & $-70.2 \%$ \\
\hline Minimum & $-17.7 \%$ & $-29.7 \%$ & $-37.6 \%$ & $-14.3 \%$ & $-45.5 \%$ & $-17.7 \%$ & $-42.89 \%$ & $-20.7 \%$ & $-24.0 \%$ & $-21.3 \%$ & $-42.7 \%$ \\
\hline Maximum & $27.6 \%$ & $25.7 \%$ & $50.0 \%$ & $22.6 \%$ & $45.9 \%$ & $26.3 \%$ & $31.0 \%$ & $15.9 \%$ & $25.6 \%$ & $25.3 \%$ & $29.4 \%$ \\
\hline \multirow[t]{3}{*}{ N } & 252 & 252 & 252 & 252 & 252 & 252 & 252 & 252 & 252 & 252 & 252 \\
\hline & & & & & & & & & & & \\
\hline & $\mathrm{CL}$ & AIS & $\mathrm{ECL}$ & USB & $\mathrm{Cl}$ & HPQ & MKC & MDO & $A Z N$ & $\mathrm{H} 5 \mathrm{BC}$ & COF \\
\hline Mean & $0.7 \%$ & $0.6 \%$ & $1.2 \%$ & $0.9 \%$ & $1.4 \%$ & $0.7 \%$ & $1.3 \%$ & $1.7 \%$ & $0.9 \%$ & $0.3 \%$ & $1.1 \%$ \\
\hline 5td. Dev. & $5.0 \%$ & $21.7 \%$ & $5.9 \%$ & $7.5 \%$ & $9.7 \%$ & $9.7 \%$ & $5.19 \%$ & $8.1 \%$ & $6.9 \%$ & $7.2 \%$ & $11.3 \%$ \\
\hline Kurtosis & $254.1 \%$ & $7067.1 \%$ & $382.9 \%$ & $493.4 \%$ & $646.0 \%$ & $119.8 \%$ & $63.28 \%$ & $88.7 \%$ & $76.6 \%$ & $239.0 \%$ & $509.4 \%$ \\
\hline Skewness & $4.1 \%$ & $629.5 \%$ & $36.1 \%$ & $-67.2 \%$ & $-89.9 \%$ & $0.0 \%$ & $-2.06 \%$ & $-26.3 \%$ & $36.8 \%$ & $30.3 \%$ & $-10.3 \%$ \\
\hline Minimum & $-16.7 \%$ & $-84.5 \%$ & $-23.0 \%$ & $-39.6 \%$ & $-520 \%$ & $-320 \%$ & $-12.58 \%$ & $-24.7 \%$ & $-20.3 \%$ & $-27.0 \%$ & $-50.3 \%$ \\
\hline Maximum & $24.5 \%$ & $245.0 \%$ & $29.9 \%$ & $28.8 \%$ & $39.1 \%$ & $36.2 \%$ & $17.89 \%$ & $28.8 \%$ & $22.8 \%$ & $28.4 \%$ & $46.0 \%$ \\
\hline \multirow[t]{3}{*}{ N } & 252 & 252 & 252 & 252 & 252 & 252 & 252 & 252 & 252 & 252 & 252 \\
\hline & & & & & & & & & & & \\
\hline & Portfolio & DILA & NASDAQ & $58 \mathrm{P} 500$ & & & & & & & \\
\hline Mean & $1.0 \%$ & $0.5 \%$ & $0.7 \%$ & $0.5 \%$ & & & & & & & \\
\hline 5td. Dev. & $4.1 \%$ & $4.3 \%$ & $6.4 \%$ & $4.4 \%$ & & & & & & & \\
\hline Kurtosis & $321.1 \%$ & $110.0 \%$ & $133.2 \%$ & $110.4 \%$ & & & & & & & \\
\hline Skewness & $-60.9 \%$ & $-48.9 \%$ & $-48.4 \%$ & $-51.2 \%$ & & & & & & & \\
\hline Minimum & $-17.6 \%$ & $-14.1 \%$ & $-22.9 \%$ & $-16.9 \%$ & & & & & & & \\
\hline Maximum & $14.2 \%$ & $11.8 \%$ & $19.2 \%$ & $12.7 \%$ & & & & & & & \\
\hline $\mathrm{N}$ & 252 & 252 & 252 & 252 & & & & & & & \\
\hline
\end{tabular}

\section{Rate of Return}

Table 1 shows that average monthly rate of return for benchmark indices-Dow Jones Industrial Average, NASDAQ, and Standard \& Poor 500, and 33 diverse companies for the period January 2000 through December 2020 . The average monthly rate of return was $0.4813 \%$ for DJIA, $0.6665 \%$ for NASDAQ, and $0.47 \%$ for S\&P 500. On average, the monthly rate of returns was higher for NASDAQ than DJIA and S\&P 500.

For the diverse companies, the average monthly returns ranged from a low of $0.2502 \%$ (HSBC) to a high of $2.1376 \%$ (Humana). Of the 33 companies, 32 had average monthly returns higher than those of the DJIA and the S\&P 500, and 28 companies had average monthly returns higher than those of the NASDAQ. Average monthly return for an equally weighted portfolio of 33 diverse companies was $0.9835 \%$, which was higher than all three benchmark indices.

From the mean analysis, we inferred that the majority of the diverse companies (85-97\%) generated greater average monthly returns than the DJIA index, NASDAQ index, and S\&P 500 index.

An equally-weighted portfolio of 33 diversified firms had an average monthly return that was more than double that of the DJIA and S\&P 500, and nearly 1.5 times greater than that of the NASDAQ.

\section{Standard Deviation}

The standard deviation is a measure of volatility that quantifies the average amount by which individual data points deviate from the mean. It assists in making the gap between the prices of a portfolio or a stock and their average price. Investors frequently use it to assess the risk of a stock or a stock portfolio. 
The DJIA has a standard deviation of $4.27 \%$, which implies that the DJIA's monthly returns vary by $4.27 \%$ around its mean rate of return. The NASDAQ has a standard deviation of $6.39 \%$, which indicates that its monthly returns vary by around $6.39 \%$. S\&P 500 has a standard deviation of $4.38 \%$, which means that the returns of the S\&P 500 fluctuate by approximately $4.38 \%$ month-over-month. The NASDAQ has more volatility than the DJIA and the S\&P 500.

The standard deviation for the monthly rates of return for 33 firms in the sample ranged from $4.93 \%$ (Southern Company) to $21.72 \%$ (American International Group [AIG]), with an average volatility of $7.61 \%$. AIG was extremely high mainly due to huge fluctuations in its stock price during the 2008 financial crisis, and its monthly rate of return ranged from $-84.5 \%$ to $244.98 \%$.

All 33 firms had a standard deviation greater than that of the DJIA and the S\&P 500, implying that diverse company stocks are more volatile and riskier than the DJIA and S\&P 500 benchmark indexes. Compared to NASDAQ, 13 firms had a smaller standard deviation and 20 had a standard deviation more than $6.39 \%$.

The standard deviation of an equally weighted portfolio of all the diverse companies was $4.09 \%$, which $\mathrm{s}$ lower than all three benchmark indexes.

Based on the standard deviation analysis, we found that the majority of the individual diverse company stocks were more volatile and riskier than the three benchmarks of the DJIA index, NASDAQ index, and S\&P 500 index. The equally-weighted portfolio, on the other hand, had less volatility and was less risky than the benchmarks.

\section{EMPIRICAL ANALYSIS}

To evaluate risk-adjusted performance of diverse companies relative to benchmark indices, we computed the Sharpe ratio, Sortino ratio, and Omega ratio. Table 2 summarizes the results for these ratios for the 33 diverse companies as well as benchmark indices of DJIA, S\&P 500, and NASDAQ.

TABLE 2

SUMMARY OF THE RISK-ADJUSTED PERFORMANCE USING SHARPE RATIO, SORTINO RATIO, AND OMEGA RATIO. RISK-ADJUSTED PERFORMANCE IS BASED ON MONTHLY RETURNS FROM JANUARY 2000 TO DECEMBER 2020

\begin{tabular}{|c|c|c|c|c|c|c|c|c|c|c|c|c|}
\hline & MAR & LYY & $A D P$ & CMCSA & $A B T$ & TM & WFC & & TGT & $\mathrm{N} \propto \mathrm{C}$ & $P G$ & TD \\
\hline Sharpe $R$ at ic & 0.14 & 0.11 & 0.13 & 0.10 & 0.18 & 0.06 & & 0.07 & 0.12 & 0.19 & 0.12 & 0.14 \\
\hline Sortino Ratic & 0.22 & 0.17 & 0.21 & 0.14 & 0.27 & 0.09 & & 0.11 & 0.20 & 0.30 & 0.16 & 0.23 \\
\hline Omega Ratic & 1.46 & 1.34 & 1.41 & 1.28 & 1.58 & 1.17 & & 1.26 & 1.38 & 167 & 1.39 & 1.49 \\
\hline & HSY & CVS & HUM & 50 & BA & EXC & ALL & & WMT & MDT & K & KEY \\
\hline Sharpe Ratic & 0.16 & 0.10 & 0.19 & 0.20 & 0.12 & 0.12 & & 0.13 & 0.08 & 0.11 & 0.10 & 0.05 \\
\hline Sortino Ratic & 0.28 & 0.15 & 0.31 & 0.30 & 0.18 & 0.18 & & 0.19 & 0.12 & 0.16 & 0.15 & 0.07 \\
\hline Omega Ratic & 1.57 & 1.30 & 1.71 & 1.69 & 1.39 & 1.37 & & 1.45 & 1.25 & 1.32 & 1.32 & 1.15 \\
\hline & $\mathrm{CL}$ & AIG & $\mathrm{ECL}$ & USB & $\mathrm{Cl}$ & HPQ. & MMC & & MCO & $A Z N$ & HSBC & COF \\
\hline Sharpe Ratic & 0.11 & 0.02 & 0.19 & 0.10 & 0.13 & 0.06 & & 0.23 & 0.20 & 0.11 & 0.02 & 0.08 \\
\hline Sortino Ratic & 0.17 & 0.04 & 0.32 & 0.14 & 0.18 & 0.09 & & 0.39 & 0.30 & 0.18 & 0.02 & 0.12 \\
\hline Omega Ratic & 1.35 & 1.10 & 1.66 & 1.33 & 1.44 & 1.17 & & 1.82 & 166 & 1.34 & 1.05 & 1.27 \\
\hline & Pnotiolin & DIA & MASOM & $=8.0 .500$ & & & & & & & & \\
\hline & Porticio & DIN & NASLAR & $30 x+200$ & & & & & & & & \\
\hline Sharpe Ratio & 0.21 & 0.08 & 0.08 & 0.08 & & & & & & & & \\
\hline Sortino Ratic & 0.31 & 0.12 & 0.12 & 0.11 & & & & & & & & \\
\hline Omega Ratic & 1.78 & 1.24 & 1.25 & 1.23 & & & & & & & & \\
\hline
\end{tabular}

\section{Empirical Analysis of Sharpe Ratio}

As shows in Table 2, Sharpe ratios for Benchmark indices were:

- DJIA: 0.0819

- NASDAQ: 0.0836 
- S\&P 500: 0.0773

Sharpe ratios for all three benchmark indexes were relatively low for the last 21 years, from December 2000 to December 2020, indicating that all three indexes have generated very little excess returns relative to risk.

Sharpe ratios for various firms ranged from 0.01664 for HSBC to 0.2349 for McCormick, with an average of 0.1203 . The Sharpe ratio average for the diverse companies was higher than the Sharpe ratio average for all three benchmark indexes.

Of the 33 companies in the sample, 26 had a Sharpe ratio higher than the DJIA and NASDAQ, and 27 had a Sharpe ratio higher than the S\&P 500, implying that most of the diverse companies (79-82\%) outperformed the benchmarks in terms of excess returns relative to risk.

The Sharpe ratio for the equally weighted portfolio of all the diversified firms was 0.2083 , indicating that the portfolio outperforms all three benchmark indexes in terms of excess returns relative to risk.

\section{Empirical Analysis of Sortino Ratio}

Table 2 also shows that over the sample period of January 2000 to December 2020, the Sortino ratios for Benchmark indices were:

- DJIA: 0.1153

- NASDAQ: 0.1173

- S\&P 500: 0.1076

The Sortino ratios for all the three benchmark indices were very low, suggesting that all the three indices have generated very little excess returns for each unit of a downside risk.

Sortino ratios for diverse companies ranged from the lowest 0.0245 (HSBC) to the highest 0.3938 (McCormick), with the average of all 33 companies at 0.1868 . The average Sortino ratios for the diverse companies were greater than all of the three benchmark indices. Of the sample of 33 companies, 27 companies had a Sortino ratio higher than that of the DJIA and the NASDAQ, and 28 companies had a Sortino ratio higher than that of the S\&P 500, which meant that most of the diverse companies (82\%-85\%) generated more excess returns than the benchmarks for each unit of a downside risk. This result was slightly better than that of the Sharpe ratio.

The Sortino ratio for the equally weighted portfolio of all the diversified firms was 0.3149 , indicating that the portfolio outperformed all three benchmark indexes in terms of excess returns for each unit of downside risk.

\section{Empirical Analysis of Omega Ratio}

Table 2 shows the results for Omega ratio for 33 diverse companies as well as DJIA, S\&P500, and NASDAQ. A larger ratio indicates that a portfolio or a stock provides more gains relative to losses for some threshold and so would be preferred by an investor.

Omega ratios for the benchmark indices were:

- DJIA: 1.244

- NASDAQ: 1.247

- S\&P 500: 1.227

For the past 21 years, the Omega ratios for all the three benchmark indices have been very low, which indicates that all the three indices have generated very little gains relative to losses.

Omega ratios for diverse companies ranged from the lowest 1.046 (HSBC) to the highest 1.819 (McCormick), with the average of 1.398. The average Omega ratios for the diverse companies were greater than all the three benchmark indices. Of the 33 companies in the sample, 28 had Omega ratio higher than that of the DJIA, the NASDAQ, and the S\&P 500, which means that most of the diverse companies (85\%) have generated more gains relative to losses, than the benchmarks have done.

The Omega ratio for the equally weighted portfolio of all the diverse companies was 1.784 , indicating that the portfolio had excellent performance, in terms of more gains relative to losses, compared to the three benchmark indices. 


\section{Analysis of Fama-French Model}

Using Fama-French model, we computed alpha for our benchmark indices: DJIA, NASDAQ, S\&P 500. For DJIA, the alpha was a negative value of -0.001072 , with the p-value of 0.1474 . DJIA underperformed the market by $-0.1072 \%$ monthly, but this underperformance was not statistically significant. R2 was 0.9276, indicating that Rm-Rf, SMB, and HML explain 92.76\% of the variation in DJIA's risk-adjusted return.

For NASDAQ, the alpha was a negative value of -0.001621 , with the p-value of 0.1265 . NASDAQ also underperformed the market by $-0.1621 \%$ monthly, and it is not statistically significant. R2 was 0.9336 , indicating that Rm-Rf, SMB, and HML explain $93.36 \%$ of the variation in NASDAQ's excess return.

For the S\&P 500, the alpha was again a negative value of -0.00161 , with an extremely small $\mathrm{p}$-value. S\&P 500 also underperformed the market, by $-0.161 \%$ monthly, which was statistically significant at $1 \%$ significance level. R2 was 0.9945 , indicating that Rm-Rf, SMB, and HML explain $99.45 \%$ of the variation in S\&P 500's excess return.

Then we computed the alpha for the diverse companies. Excess monthly returns of diverse companies were regressed against Rm-Rf, SMB, and HML, respectively.

For the equally weighted portfolio of all of the diverse companies, the alpha was 0.004416 , and it was statistically significant at any level. R2 was 0.8487 , indicating that Rm-Rf, SMB, and HML explain 84.87\% of the variation in the equally weighted portfolio's excess return. Of the 33 companies, 7 had negative alpha, but the negative alpha was not statistically significant. Alpha was positive for 26 companies but was statistically significant for only 8 companies in the sample.

TABLE 3

SUMMARY OF RISK ADJUSTED PERFORMANCE OF 33 MOST DIVERSE COMPANIES, EQUALLY WEIGHTED PORTFOLIO OF 33 DIVERSE COMPANIES, DJIA, NASDAQ, AND S\&P500. RISK-ADJUSTED PERFORMANCE IS BASED ON FAMA-FRENCH MODELS THREE FACTOR MODEL, CARHART FOUR FACTOR MODEL, AND FAMA-FRENCH FIVE FACTOR MODEL USED IN THIS STUDY. RISK-ADJUSTED PERFORMANCE IS MEASURED BASED ON MONTHLY RETURNS FROM JANUARY 2000 TO DECEMBER 2020

\begin{tabular}{|c|c|c|c|c|c|c|c|c|c|c|c|}
\hline \multicolumn{2}{|c|}{ MAR } & \multirow{2}{*}{$\begin{array}{ll}\text { UY } & \\
& 0.56 \%\end{array}$} & \multirow{2}{*}{$\begin{array}{l}\text { ADP } \\
\quad 0.42 \%\end{array}$} & \multicolumn{2}{|c|}{ CMCSA ABT } & \multirow{2}{*}{ TM $-0.01 \%$} & \multirow{2}{*}{$\begin{array}{l}\text { WFC } \\
0.06 \%\end{array}$} & \multirow{2}{*}{ TGT $0.49 \%$} & \multirow{2}{*}{ NOC } & $P G$ & \multirow{2}{*}{ TD $\quad 0.39 \%$} \\
\hline Three-Factor & $0.39 \%$ & & & $0.19 \%$ & $0.85 \%$ & & & & & 0.468 & \\
\hline p-value & 0.284 & 0.192 & 0.173 & 0.590 & 0.011 & 0.987 & 0.859 & 0.255 & 0.009 & 0.139 & 0.200 \\
\hline Four-Factar & $0.60 \%$ & $0.55 \%$ & $0.42 \%$ & $0.18 \%$ & $0.79 \%$ & $0.07 \%$ & $0.15 \%$ & $0.61 \%$ & $0.9 \%$ & $0.45 \%$ & $0.44 \%$ \\
\hline P-value & 0.073 & 0.203 & 0.173 & 0.624 & 0.018 & 0.846 & 0.661 & 0.148 & 0.013 & 0.156 & 0.150 \\
\hline Five Factor & $0.13 \%$ & $0.36 \%$ & $0.29 \%$ & $0.02 \%$ & 0.568 & $0.16 \%$ & $0.21 \%$ & $0.12 \%$ & $0.73 \%$ & $0.10 \%$ & $0.60 \%$ \\
\hline p-walue & 0.724 & 0.410 & 0.365 & 0.959 & 0.106 & 0.647 & 0.563 & 0.796 & 0.064 & 0.759 & 0.059 \\
\hline \multicolumn{2}{|c|}{ HSY } & cus & HUM & So & $B A$ & DXC & All & WMT & MDT & K & KEY \\
\hline Three-Factor & $0.92 \%$ & $0.39 \%$ & $1.57 \%$ & $0.93 \%$ & $0.50 \%$ & $0.55 \%$ & $0.52 \%$ & $0.34 \%$ & $0.30 \%$ & $0.34 \%$ & $-0.11 \%$ \\
\hline P-value & 0.012 & 0.363 & 0.010 & 0.002 & 0.296 & 0.137 & 0.159 & 0.283 & 0.368 & 0.283 & 0.793 \\
\hline Four-Factor & $0.88 \%$ & $0.35 \%$ & $1.48 \%$ & $0.84 \%$ & $0.53 \%$ & $0.50 \%$ & $0.51 \%$ & $0.34 \%$ & $0.26 \%$ & $0.35 \%$ & $-0.14 \%$ \\
\hline P-value & 0.017 & 0.416 & 0.015 & 0.005 & 0.267 & 0.178 & 0.170 & 0.293 & 0.436 & 0.270 & 0.749 \\
\hline Five Factor & $0.63 \%$ & $-0.04 \%$ & $1.16 \%$ & $0.64 \%$ & $0.30 \%$ & $0.29 \%$ & $0.27 \%$ & $0.09 \%$ & $0.31 \%$ & $-0.01 \%$ & $0.10 \%$ \\
\hline p-value & 0.101 & 0.934 & 0.066 & 0.040 & 0.545 & 0.458 & 0.490 & 0.776 & 0.385 & 0.969 & 0.835 \\
\hline \multicolumn{2}{|c|}{ a } & AIG & ECL & USB & $\mathrm{Cl}$ & $H P Q$ & MKC & $\mathrm{MCO}$ & $A Z N$ & HSBC & COF \\
\hline Three-Factor & $0.39 \%$ & $-0.60 \%$ & $0.78 \%$ & $0.24 \%$ & $0.67 \%$ & $-0.17 \%$ & $1.03 \%$ & $1.07 \%$ & $0.55 \%$ & $-0.41 \%$ & $-0.02 \%$ \\
\hline P-walue & 0.178 & 0.628 & 0.011 & 0.469 & 0.223 & 0.722 & 0.001 & 0.015 & 0.175 & 0.263 & 0.967 \\
\hline Four-Factor & $0.35 \%$ & $-0.44 \%$ & $0.78 \%$ & $0.30 \%$ & $0.72 \%$ & $-0.12 \%$ & $0.97 \%$ & $1.07 \%$ & $0.51 \%$ & $-0.30 \%$ & $0.08 \%$ \\
\hline p-value & 0.222 & 0.724 & 0.012 & 0.368 & 0.192 & 0.804 & 0.002 & 0.016 & 0.206 & 0.396 & 0.853 \\
\hline Five Factor & $0.03 \%$ & $0.35 \%$ & $0.34 \%$ & $0.35 \%$ & $0.59 \%$ & $0.24 \%$ & $0.53 \%$ & $0.89 \%$ & $0.32 \%$ & $-0.11 \%$ & $0.46 \%$ \\
\hline P-value & 0.924 & 0.784 & 0.277 & 0.320 & 0.307 & 0.624 & 0.086 & 0.051 & 0.450 & 0.770 & 0.351 \\
\hline \multicolumn{2}{|c|}{ Portfalia } & DILA & NASDAQ & S\&P 500 & & & & & & & \\
\hline Three-Factor & 0.449 & $-0.11 \%$ & $-0.16 \%$ & $-0.16 \%$ & & & & & & & \\
\hline p-value & 0.000 & 0.147 & 0.126 & 0.000 & & & & & & & \\
\hline Four-Factor & $0.45 \%$ & $-0.10 \%$ & $-0.14 \%$ & $-0.15 \%$ & & & & & & & \\
\hline P-value & 0.000 & 0.188 & 0.188 & 0.000 & & & & & & & \\
\hline Five Factor & $0.33 \%$ & $-0.24 \%$ & $0.13 \%$ & $-0.19 \%$ & & & & & & & \\
\hline P-value & 0.002 & 0.001 & 0.176 & 0.000 & & & & & & & \\
\hline
\end{tabular}




\section{Empirical Analysis of Carhart's Four Factor Model}

For DJIA, the alpha was a negative value of -0.000974 , with the p-value of 0.1884 . DJIA underperformed the market by $-0.0974 \%$ monthly over January 2000 to December 2020, but this underperformance was not statistically significant. R2 was 0.9282 , indicating that Rm-Rf, SMB, HML, and MOM explain $92.82 \%$ of the variation in DJIA's excess return.

For NASDAQ, the alpha was a negative value of -0.001385 , which was not statistically significant. R2 was 0.9353 , indicating that Rm-Rf, SMB, HML, and MOM explain 93.53\% of the variation in NASDAQ's excess return.

For S\&P 500, the alpha had a negative value of -0.00153 , with an extremely small p-value. S\&P 500 also underperformed the market, by $-0.153 \%$ monthly, which was statistically significant at any level. R2 was 0.9949 , indicating that Rm-Rf, SMB, HML, and MOM explain 99.49\% of the variation in S\&P 500's excess return.

We then computed alpha for the diverse companies. Excess monthly returns of diverse companies were regressed against Rm-Rf, SMB, HML, and MOM, respectively.

For the equally-weighted portfolio of all the diverse companies, the alpha was 0.004545 , and the pvalue was 0.0000128 . The equally-weighted portfolio outperformed the market by $0.4545 \%$ monthly, which was statistically significant at any level. R2 was 0.8499 , which indicated that Rm-Rf, SMB, HML, and MOM explain $84.99 \%$ of the variation in the equally weighted portfolio's excess return.

The results for alpha and R2 of the Carhart four-factor model were very similar to that of the FamaFrench three-factor model, indicating that the additional momentum factor had very little impact on the equally-weighted portfolio.

\section{Empirical Analysis of Fama-French Five Factor Model}

We also evaluated the risk-adjusted performance of diverse companies based on the Fama-French fivefactor model. We computed alpha for our benchmark indices: DJIA, NASDAQ, S\&P 500. Excess monthly returns of DJIA, NASDAQ, S\&P 500 were regressed against Rm-Rf, SMB, HML, RMW, and CMA, respectively.

For DJIA, the alpha was a negative value of -0.002437 , with a p-value of 0.000857 . DJIA underperformed the market by $-0.2437 \%$ monthly, which was statistically significant at any level. R2 was 0.9376, indicating that Rm-Rf, SMB, HML, RMW, and CMA explains $93.76 \%$ of the variation in DJIA's excess return.

For NASDAQ, the alpha changed from negative to positive 0.001298 , with the p-value of 0.1755 . NASDAQ has outperformed the market, by $0.1298 \%$ monthly, but the alpha was not statistically significant. R2 is 0.9512, indicating that Rm-Rf, SMB, HML, RMW, and CMA explains $95.12 \%$ of the variation in NASDAQ's excess return.

For S\&P 500, the alpha was again a negative value of -0.00189 , with an extremely small p-value. S\&P 500 also underperformed the market, by $-0.189 \%$ monthly, which was statistically significant at any level. R2 was 0.9949, indicating that Rm-Rf, SMB, HML, RMW, and CMA explain $99.49 \%$ of the variation in S\&P 500's excess return.

Then we computed the alpha for the diverse companies. For the equally-weighted portfolio of 33 diverse companies, the alpha was 0.003334 . The equally-weighted portfolio outperformed the market by $0.3334 \%$ monthly, which was statistically significant at any level. R2 was 0.8532 , indicating that Rm-Rf, SMB, HML, RMW, and CMA explain $85.32 \%$ of the variation in the equally weighted portfolio's excess return.

Only 2 companies had a statistically insignificant alpha. All other diverse companies had a positive five-factor alpha. Six companies had alpha that was statistically significant. We concluded that diverse companies, as well as the equally-weighted portfolio, outperformed the market under multiple-factor models. 


\section{SUMMARY AND CONCLUSIONS}

The influence of racial and gender diversity on companies and teams is a hotly discussed issue in today's corporate world. The diversity debate focuses on the consequences of variety on analytical thinking and on innovative thinking. Researchers have struggled to show a causal link between diversity and "harder" financial performance indicators. This study examined the effects of diversity on the risk-adjusted performance of stocks from 33 of the most diverse corporations. We found that most of the diverse companies provided average monthly returns higher than the DJIA index, NASDAQ index, and S\&P 500 index.

An equally-weighted portfolio of 33 diversified firms had an average monthly return that was more than double that of the DJIA and S\&P 500, and nearly 1.5 times greater than that of the NASDAQ. A simple standard deviation analysis showed that us that most of the individual diverse company stocks were more volatile and riskier than the three benchmarks of the DJIA index, NASDAQ index, and S\&P 500 index. The equally-weighted portfolio, on the other hand, had less volatility and was less risky than the benchmarks.

Using typical portfolio performance indicators, we examined risk-adjusted performance from 2000 to 2020. We discovered that, in most circumstances, diverse firms outperformed stock market benchmark indexes. We also discovered that an equally weighted portfolio of the 33 most diverse firms outperformed the risk-adjusted performance of the DJIA, the S\&P 500 index, and the NASDAQ. Under the Fama-French three-factor model and the Carhart four-factor model, our three benchmark indices of DJIA, NASDAQ, and S\&P 500 all had statistically significant negative alpha, which means that they all underperformed the market. Meanwhile, none of the diverse companies had statistically significant negative alpha, but rather most of them had statistically significant positive alpha, which means that the equally weighted portfolio had excellent performance.

\section{REFERENCES}

Andrevski, G., Richard, O.C., Shaw, J.D., \& Ferrier, W.J. (2014). Racial diversity and firm performance: The mediating role of competitive intensity. Journal of Management, 40(3), 820-844.

Richard, O.C. (2000). Racial diversity, business strategy, and firm performance: A resource-based view. Academy of Management Journal, 43(2), 164-177.

Roberson, Q.M., \& Hyeon, J.P. (2007). Examining the link between diversity and firm performance: The effects of diversity reputation and leader racial diversity. Group \& Organization Management, $32(5), 548-568$.

Vairavan, A., \& Zhang, G.P. (2020). Does a diverse board matter? A mediation analysis of board racial diversity and firm performance. Corporate Governance, 20(7), 1223-1241. 